Article

\title{
Dynamic Behaviour Adaptation of Lightweight Structures by Compressible Constrained Layer Damping with Embedded Polymeric Foams and Nonwovens
}

\author{
Tom Ehrig *๑, Klaudiusz Holeczek $₫$, Niels Modler $\unrhd$ and Pawel Kostka \\ Institute of Lightweight Engineering and Polymer Technology, Technische Universität Dresden, \\ 01307 Dresden, Germany \\ * Correspondence: tom.ehrig@tu-dresden.de
}

Received: 30 June 2019; Accepted: 20 August 2019; Published: 23 August 2019

check for updates

Featured Application: Mitigating vibrations of flat, large-scale structures, for example, car front wall or ceiling, as well as structural and/or cover parts for rail vehicles or noise barriers of different kinds. Furthermore adaptable compact dampers, for example, machine feet are also a promising application field for the proposed novel damping approach.

\begin{abstract}
Evanescent morphing in combination with an original concept of Compressible Constrained Layer Damping (CCLD) is a novel and promising approach for dynamic behaviour adaptation. The crucial component of the CCLD is a compressible intermediate layer with its thickness and material properties controlled by fluid actuation, enabling the adjustment of the damping and stiffness of the overall system. To estimate the potential of the CCLD, an analytical model was developed which describes the vibration behaviour of the overall structure, taking into account the compression-driven properties of the intermediate layer. The results confirm the principal correctness of the initial theoretical assumptions regarding the adaptive dynamic behaviour of structures with CCLD treatment. A significant vibration mitigation as well as a high adaptability of dynamic behaviour were observed, however, they show a complex dependence on the system configuration. Nevertheless, the developed analytical modelling approach can already be used for a preliminary system design. Besides the analysed polymer-based foams as the intermediate layer, nonwovens also exhibit compression-dependent shear properties and can therefore be used in CCLD. First preliminary investigations show that the damping performance is on average about ten times better than that of the polymeric foams.
\end{abstract}

Keywords: compressible constrained layer damping; adaptive vibration damping; evanescent morphing; semi-active damping adaptation; polymeric foams; nonwovens

\section{Introduction}

Improving the energy efficiency and achieving new performance levels of vehicles, machines and facilities is a continuous challenge for engineering and science. As an indispensable instrument for this goal, a consistent implementation of lightweight construction principles has been widely recognised. Integral design with a reduced number of joints as well as hybrid materials combining polymers, ceramics, lightweight alloys and composites offer the possibility to develop components with material effort optimised for the distribution of the operational loads. Fibre-reinforced plastics with "tailored" reinforcement especially enable an application-dependent trade-off between stiffness and damping combined with a damage tolerant design of dynamically loaded components [1-4]. 
An ultimately stiffness/strength-oriented design, however, often causes a problematic vibration susceptibility, especially of common thin-walled components and makes the application of additional damping measures necessary. A number of such measures are being fundamentally conceptualised, mathematically and numerically modelled, as well as experimentally validated in numerous scientific projects. Herein, some recent representative examples include:

- $\quad$ special sandwich panel cores, for example, in form of truss structures combined with intermediate layers of damping materials [5] or filled with granular materials [6], including cores with voids of optimised geometries [7],

- locally acting dampers such as compact acoustic black holes [8,9], structurally integrated resonant metamaterials [10] and joints with viscoelastic damping [11],

- active magneto-/electro- or photorheological layers with the damping and stiffness controlled by magnetic, electric field or light, respectively [12-16],

- $\quad$ extended concepts of shunted piezoelectric actuator systems [17-20],

- distributed active damping systems that use numerous vibration sensors and actuators attached to complex shaped structures, driven by real-time controllers [21,22].

Most of these damping approaches achieved very good results. However, the total implementation costs of semi-active and especially of active damping systems are still high; also the additional mass of the structure-integrated and peripheral hardware is an essential drawback for many applications.

Modelling, design and manufacturing methods that address the principle of passive damping layers are being further developed. Especially treatments belonging to the family of Constrained Layer Damping (CLD) in which damping layers are forced to shear deformations while the base structure vibrates in bending modes are applied for structures with complex geometries [23,24]. Partial coverage with CLD segments of optimised shape is a common measure enabling a reduction of the mass overhead caused by the damping treatment [25].

On the one hand, the material configuration of CLD has not essentially changed for a long time. Bitumen- and rubber-based viscoelastic materials with some modifications, for example, particle addition, are still used, sometimes in combination with piezoelectric materials allowing an active behaviour of the damping treatment [26]. A concept followed in this publication, namely the replacement of the an uncompressible damping layer with a compressible one was considered until now solely by the authors $[27,28]$. The compressibility of the damping layer can be achieved by the application of open-cell foams. This requires, however, in addition to appropriate modelling, sufficient material data, in particular regarding shear behaviour under compression. The monoaxial compressional behaviour of polymer-based open-cell foams has been already investigated [29-31]. The shear behaviour of open cell foams has so far only been investigated by Reference [32] but without precompression of the foams.

On the other hand, although the idea of using technical textiles as dissipative materials, including their conventional classes [33] and novel synthetic structural materials [34] is well known, they are-as to the knowledge of the authors-not used in unconsolidated condition in CLD treatments. Therefore, this publication addresses the following main objectives: (I) to demonstrate the capability of the CLD with compressible intermediate layer, (II) to present an analytical approach with which a preliminary system design is possible and (III) to estimate the potential of a new class of materials for the intermediate layer, namely nonwovens.

\section{Operating Principle of Compressible Constrained Layer Damping and Polymeric Foam Characterisation}

For the adaptation of the dynamic behaviour, an original concept of Compressible Constrained Layer Damping (CCLD) was already proposed by the authors in previous publications $[27,28]$. CCLD is an extension of the well-known CLD design, where the usually incompressible viscoelastic damping layer is replaced by a compressible one. Thus the adaptation principle of CCLD is based on the 
pressure-controlled thickness variation of the viscoelastic damping layer (Figure 1). While the storage and loss shear modulus of the viscoelastic layer $\left(G^{\prime}\right.$ and $G^{\prime \prime}$, which significantly affect the damping performance) and the thickness of the viscoelastic layer are constant for CLD, in the case of the CCLD they depend on the actuating pressure $p_{1}$. The through-thickness actuation of the viscoelastic damping layer by $p_{1}$ and the altering of the shear deformation amplitude $\hat{\gamma}_{1}$ due to variable damping layer thickness $h_{1}$ results finally in a simple yet efficient adaptation of the dynamic behaviour of the overall system. The actual damping mechanism is based, as for CLD, on the shear induced within the constrained damping layer.

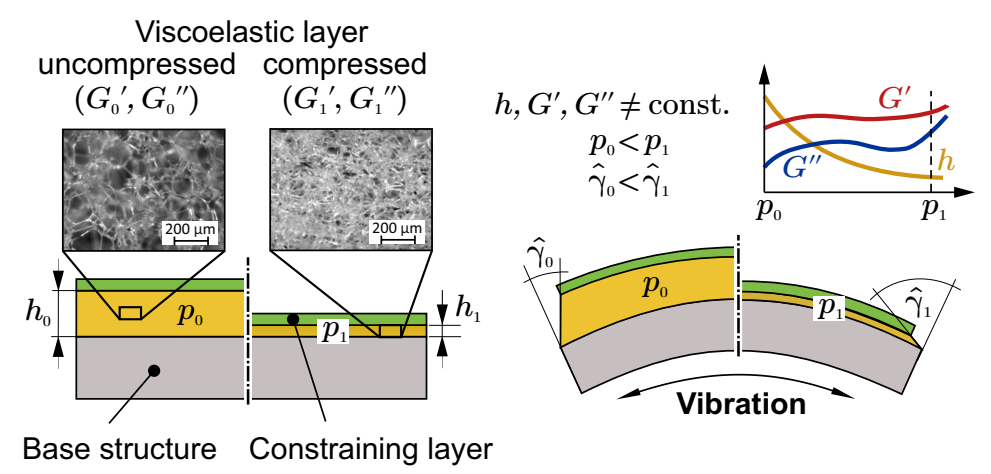

Figure 1. The Compressible Constrained Layer Damping (CCLD) setup is an extension of the well-known Constrained Layer Damping (CLD) design, usually applied for attenuating of bending vibrations. The typical incompressible viscoelastic damping layer is replaced in the CCLD by a compressible one; the adaptable dynamic shear behaviour results from the compacting of the damping material (by an actuating pressure $p_{1}$ ) and from the altering of the shear deformation amplitude $\hat{\gamma}_{1}$ due to variable damping layer thickness $h_{1}$.

The underlying control principle bases on slight deformations ("evanescent morphing") when actuated by, for example, hydraulic fluid, compressed air or vacuum. In the presented work, exclusively vacuum actuation is considered. As a result, in the following investigations, the viscoelastic layer can only be compressed with a (negative) pressure of up to 1 bar from its uncompressed initial state. The here used term "evanescent morphing" means such a small shape change of the relevant dimension (e.g., thickness) of the oscillating structure that it only influences its dynamic behaviour, whereas the influence on the primary load carrying function is negligible.

While the CCLD principle can be realised with a variety of intermediate layer materials, following material characteristics were identified as vital:

- high damping to influence the structural dynamic behaviour using the minimal deformation through actuation principle,

- $\quad$ strong compression dependency of shear material properties to achieve a broad adjustment range of structural dynamic properties,

- high permeability for the actuation fluid and a technically feasible relation between compressive stress and compression, for example, allowing a considerable compression under vacuum actuation,

- low density to suit the lightweight aspect.

An extensive product research of commercial flexible polymer foams revealed the unavailability of sufficient quantitative specifications of material properties related to the above mentioned characteristics, hampering a direct selection of suitable materials. Especially the relation between the applied pressure and the resulting compression as well as the accompanying change of shear dynamic properties are of key importance for the assessment of the CCLD potential as an adaptive damping treatment. They, however, could not be found for any compressible material even in specialised scholar publications. Therefore, a preselection of materials was conducted taking into account 
merely the available information about basic material features and the final selection was made based on the self conducted experimental material characterisation. Since the material density is an important lightweight indicator and it influences the damping as well as determines indirectly the actuation-relevant porosity of the foam, a broad range of the densities was used as an initial selection criterion of damping materials. This led to the selection of twelve open cell polyurethane (PU) foams and a single melamine foam. The loss and storage moduli were determined in preliminary rheometric tests (as described later in detail) for a single frequency of $f=1 \mathrm{~Hz}$. For a further selection of suitable materials, it was judged to be advantageous that the foams could be compressed to at least $88 \%$ with a pressure of 1 bar (corresponding to the maximum possible pressure when actuated by vacuum), since major changes of the shear properties were expected in the range of high compression. Out of the foams that fulfilled this criteria, the two foams with the highest loss modulus (foam $C$ and $D$ ) and foam B (with the lowest density and the associated high lightweight potential) as well as foam A (melanin-based; as a material with fundamentally different open cell morphology compared to PU foams) were selected. Thus, four foams were finally chosen for further investigations and characterised in detail.

The CCLD-relevant properties (Table 1) were determined based on procedures described in DIN EN ISO 845:2009-10 (density), DIN EN ISO 11357-2:2014-07 (glass transition temperature) and ASTM D 3576 (cell diameter of PU foams; due to different morphology, a similar procedure was derived for the melamine foam).

Table 1. Selected physical and geometrical/morphological properties of the investigated foams [35].

\begin{tabular}{|c|c|c|c|c|c|c|c|}
\hline Sample & Manufacturer & Type Name & Base & $\begin{array}{l}\text { Density } \\
\mathrm{kg} \mathrm{m}^{-3}\end{array}$ & $\begin{array}{c}\text { Porosity } \\
-\end{array}$ & $\begin{array}{l}\text { Glass Transition } \\
\text { Temperature }{ }^{\circ} \mathrm{C}\end{array}$ & $\begin{array}{c}\text { Cell } \\
\text { Diameter mm }\end{array}$ \\
\hline Foam A & BASF SE & Basotect ${ }^{\circledR}$ G+ & $\begin{array}{l}\text { Melamine } \\
\text { resin }\end{array}$ & 9.0 & 0.994 & $\mathrm{n} / \mathrm{a}$ & 12.5 \\
\hline Foam B & $\begin{array}{c}\text { Schaumstoffe } \\
\text { Wegerich GmbH }\end{array}$ & RG1720 & PU & 16.3 & 0.986 & -53.97 & 3.0 \\
\hline Foam C & $\begin{array}{c}\text { Schaumstoffe } \\
\text { Wegerich GmbH }\end{array}$ & Visco5030 & PU & 48.4 & 0.960 & -17.48 & 3.1 \\
\hline Foam D & $\begin{array}{c}\text { Aearo } \\
\text { Technologies LLC }\end{array}$ & $\begin{array}{c}\text { Confor }{ }^{\mathrm{TM}} \mathrm{M} \\
\mathrm{CF}-40\end{array}$ & PU & 96.2 & 0.919 & -2.05 & 2.5 \\
\hline
\end{tabular}

All experiments related to the compression behaviour and viscoelastic shear properties were conducted on cylindrical specimens using a rotatory rheometer (MCR 502, Co. Anton Paar) in plate-plate mode. Herein, a compressive stress up to $100 \mathrm{kPa}$ was applied, anticipating a vacuum driven CCLD actuation. A detailed description of the test setup and the measurements performed can be found in Reference [35]. At first, the quasistatic through thickness compression behaviour of these materials, which determines the actuation characteristics of the CCLD, was investigated. Considering the relation between the compressive stress and strain, a non-linear behaviour with three typical regions [36] can be distinguished for all tested foams: cell wall bending, cell wall buckling and foam densification (shown exemplary for the foam D on Figure 2). As mentioned above in the selection criteria for the foams, all tested foams could be densified at least up to $88 \%$ using atmospheric pressure. In order to understand the deformation kinematics and to assess the compression reversibility at such high densifications, high-resolution in situ computed tomography (CT) enabling X-ray scanning in deformation controlled mode, was used (Figure 2). It was found that even if the tested foams were compacted to one tenth of their initial thickness, they would return to their undamaged initial structure after relief.

In the scope of material characterisation and following modelling of the structural dynamic behaviour, a linear viscoelastic model of the foams as damping material was assumed. Such assumption was verified based on the analyses of raw rheometric data revealing harmonic, phase shifted stress response on applied harmonic strain. Therefore, the well established description of the viscoelastic properties using the complex shear modulus $G^{*}=G^{\prime}+i G^{\prime \prime}$ was applied, where $G^{\prime}$ is the stiffness related storage shear modulus and $G^{\prime \prime}$ is the damping related loss shear modulus. The complex 
shear modulus depending on compression-which determines the adaptable stiffness and damping properties of the CCLD treatment-was characterised in shear rheometric tests conducted at different frequencies and temperatures for at least eight compressions between $5 \%$ (this minimal value was determined as necessary for a reliable load introduction in the shear testing mode) and $88 \%$. The applied experimental procedure allows a transformation of the test data to a frequency range that is much broader than the testing machine's frequency span (here $0.1 \ldots 16 \mathrm{~Hz}$ ) using the time-temperature superposition (TTS) principle [35]. The spans of test temperatures and frequencies were selected in such a way that the measured data could be extrapolated for a fixed operating temperature of $23^{\circ} \mathrm{C}$ into a new frequency range ending at $10^{4} \mathrm{~Hz}$, what required 2304 independent rheometric tests. Additionally, quasistatic compression tests were conducted to determine the compressive stress versus deformation describing the actuation behaviour of the CCLD being significantly slower compared to shear deformation rates during the CCLD-damped oscillations. This means that both the slow compressive actuation of the damping layer with its significant volume changes and fast shear oscillations with slight volume changes led to small fluid flow rates. Hence, the authors have assumed that the influence of damping effects connected with fluid flow in the cell skeleton can be neglected for the operation modes actuation and damping of the CCLD system at the present research stage. Such assumption is necessary for the application of the TTS as a principle pertaining originally to the behaviour of solid polymer materials. Moreover, in the literature, for example, Reference [32], it has been shown that this approach is valid for polymeric foam materials.
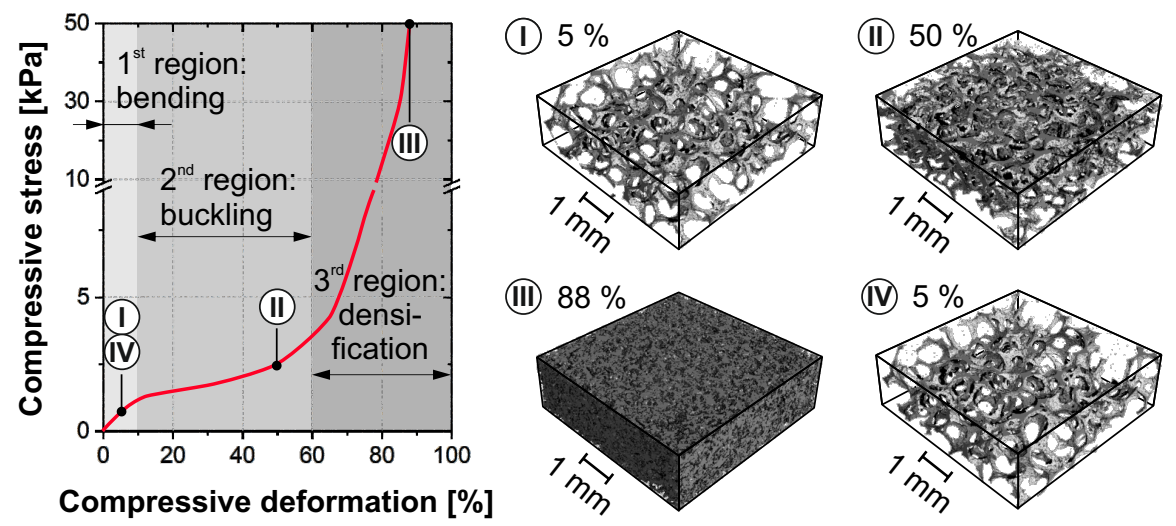

Figure 2. Compressive stress versus deformation with in situ computed tomography (CT) images of foam D at (I) $5 \%$, (II) $50 \%$, (III) $88 \%$ compression and (IV) after relief of the compression force again at $5 \%$ compression.

A primary result of the conducted material characterisation is a catalogue of quantitative material data, which can be used in the CCLD design. In addition, some comparative characteristics were formulated and calculated as shown in Table 2. Both of these results, revealing a complex picture, can be used as the necessary basis for the design and calculation of structures with CCLD.

Table 2. Key indicators of the tested foam materials at $f=100 \mathrm{~Hz}$ and $T=23^{\circ} \mathrm{C}$ to select the material for the viscoelastic damping layer according to individual requirements [35]. More detail on the change of the shear moduli as a function of compression could be find in the Appendix A (Figure A1).

\begin{tabular}{|c|c|c|c|c|c|c|c|c|c|}
\hline & \multicolumn{2}{|c|}{ Storage Modulus $G^{\prime}$} & \multicolumn{2}{|c|}{ Loss Modulus $G^{\prime \prime}$} & \multirow{2}{*}{$\begin{array}{c}\text { Loss Modulus per Density } \\
88 \% \mathrm{kPa} \mathrm{m}^{-3} / \mathrm{kg}\end{array}$} & \multicolumn{2}{|c|}{ Adaptive Capability of $G^{\prime}$} & \multicolumn{2}{|c|}{ Adaptive Capability of $G^{\prime \prime}$} \\
\hline & $5 \% \mathrm{kPa}$ & $88 \% \mathrm{kPa}$ & $5 \% \mathrm{kPa}$ & $88 \% \mathbf{k P a}$ & & $5-88 \%-$ & $50-88 \%-$ & $5-88 \%-$ & $50-88 \%-$ \\
\hline Foam A & 98.8 & 466.4 & 5.1 & 106.9 & 11.8 & 4.7 & 8.6 & 20.9 & 20.9 \\
\hline Foam B & 28.7 & 155.7 & 2.7 & 25.0 & 1.5 & 5.4 & 8.4 & 9.5 & 13.8 \\
\hline Foam C & 145.0 & 1685 * & 316.7 & 1593 * & 32.9 & $11.6^{\dagger}$ & $14.3^{\dagger}$ & $5.0^{+}$ & $5.9^{+}$ \\
\hline Foam D & 313.8 & 2062 & 263.5 & 1463 & 15.2 & 6.6 & 8.4 & 5.6 & 7.2 \\
\hline
\end{tabular}

${ }^{*}$ Measured at $90 \%$ compression. ${ }^{\dagger}$ For 5-90\% respectively $50-90 \%$ compression. 


\section{Modelling of Lightweight Structures with Ccld Treatment}

For the estimation of the CCLD potential, a parametric model based on analytical relations of a classical CLD treatment was developed. The considered beam with CCLD is schematically shown in Figure 3. The mechanical and physical properties of the layers are denoted by subscripts $s, v, c$ for beam structure, viscoelastic and constraining layer, respectively. The width of all layers is denoted as $b$.

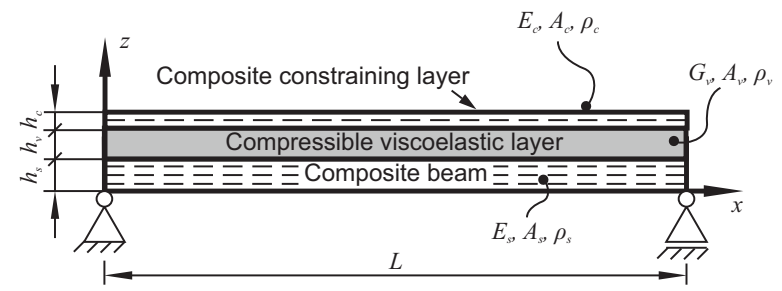

Figure 3. Configuration of the simply supported beam with CCLD analysed within the study.

To analyse the CCLD principle, a CLD model presented by Zheng [37] has been extended by the possibility of the compression-driven modification of the viscoelastic layer's geometrical and material properties. The initial Zheng model was elaborated following the assumptions:

1. All three layers have the same transverse deflection when bended;

2. Shear strains in the base layer and constraining layer and also the rotary inertia of all layers are negligible;

3. The viscoelastic layer carries transverse shear but no normal stresses. A frequency-dependent, complex shear modulus, $G_{v}(\omega)^{*}=G_{v}(\omega)\left[1+i \eta_{v}(\omega)\right]$ where $\eta_{v}(\omega)$ is the determined loss factor, is used for the description of the dynamic behaviour of the layer;

4. All displacements are small compared to the structural dimensions and hence linear theories of elasticity and viscoelasticity can be used;

5. The interfaces of the layers are characterised by the lack of slipping;

6. The plane transverse to the middle plane remains plane under bending.

The deformation pattern of the CCLD-beam at a given compression level is presented in Figure 4. The extension of the classical Zheng model of CLD for the analysis of structures with CCLD consists in the implementation of the possibility of compression-driven change of viscoelastic layer $\epsilon$ properties. The impact of the compression level on the following features is introduced:

- Thickness of the viscoelastic layer $h_{v}$

- Density of the viscoelastic layer $\rho_{v}$

- Storage shear modulus of the viscoelastic layer $G_{v}$

- Loss factor of the viscoelastic layer $\eta_{v}$

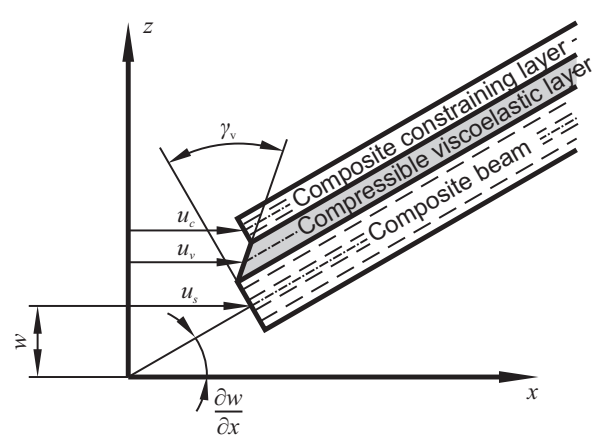

Figure 4. Deformation pattern of the considered model of the beam with CCLD treatment at a given compression level (drawing after Reference [37]). 
The volume of the damping layer during the CCLD actuation in thickness direction is changing according to the compression ratio. The mass of the whole system was assumed as constant by neglecting the variable oscillating air mass. In short, the equation of motion for generalized displacements yields:

$$
[M]\{\ddot{q}(t)\}+[K]\{q(t)\}=\{P(t)\}
$$

with: $[M]$ and $[K]$ generalized mass and stiffness matrices of the whole system, which $[K]$ is a complex matrix including the viscoelastic properties of the damping layer; $\{P(t)\}$ is the vector of generalized forces; and $\{q(t)\}$ is the displacement vector.

The system's dynamic response is determined for steady-state harmonic excitation. After introduction of the time dependence, $e^{j \omega t}$ in Equation (1):

$$
\{q(t)\}=\{\hat{q}\} e^{j \omega t} ; \quad\{P(t)\}=\{\hat{P}\} e^{j \omega t}
$$

the complex differential equation simplifies to linear system expressed as:

$$
\left[-\omega^{2} M+K\right]\{\hat{q}\}=\{\hat{P}\}
$$

The full derivation for modelling the simply supported beam with fluidically actuated CCLD can be found in Reference [38].

The linear system (Equation (3)) is solved numerically for $\{\hat{q}\}$ at each frequency of interest resulting in frequency response curves covering a desired frequency range. Such procedure was conducted using a material parameters obtained during the described material characterisation for an exemplary geometry of the vibrating system. The model was used in a series of simulations to estimate the CCLD potential regarding the damping capacity and its adaptation as well as to understand the physical relationships of parameters describing the system configuration. To study the influence of the base beam slenderness on the CCLD performance, the length of the base beam was kept constant at $550 \mathrm{~mm}$ while its thickness was varied in such a way that the slenderness took the values of 10, 20 and 100. The base beam component of the model was configured with the homogenised viscoelastic properties of a $\left[0,90,0_{4}\right]_{\mathrm{s}}$ lay up of unidirectional prepreg layers (T700 carbon fibres and epoxy resin) with a low intrinsic structural damping, implemented using a loss factor typical for the material type and its lay up. The constraining layer was assumed as one unidirectional ply of T700 carbon fibres and epoxy resin of the thickness $0.25 \mathrm{~mm}$. The parameters of the viscoelastic layer were consecutively set according to material characterisation results for the foams shown in Table 1. The TTS principle, applied to the primary rheometric data, enabled simulations in an augmented frequency range at fixed temperatures for all considered foams.

Since the shear deformation of the viscoelastic layer during the beam bending vibrations increases with the decrease of its thickness, possibly thin layers were pursued in order to maximise the damping effect. Thus, the lower thickness limit in uncompressed state was set for each foam to exactly 10 mean foam cell diameters.

The normal displacement amplitude at the middle of the beam $L / 2$ as a response to a unit, normal harmonic excitation force applied in the same point was calculated for every above mentioned slenderness value and foam material. The change of the dynamic behaviour in comparison with the bare beam behaviour and the adaptation range that defines how much the vibration amplitudes can be changed using the CCLD actuation, were used as key effectiveness indicators. They are presented in detail in Figure 5 for the complete analysed frequency range on example of foam $\mathrm{D}$ and slenderness value of 100. Results obtained for all considered foam materials and slenderness values are compactly presented in Figure 6 for the bending modes 1, 3 and 5.

It can be observed that already the application of an unactuated CCLD (Figure 5B) on the bare beam significantly increases the damping and reduces the vibration amplitudes. This can be accounted to a purely passive CLD treatment influence and it can pose a favourable fail-safe system 
feature in real applications. Both the adjustment range and the damping capacity reveal a complex dependency on the system configuration, varied here in terms of beam slenderness and damping material. An understandable trend showing decreasing vibration amplitudes for more slender beams can be directly seen (Figure $6 \mathrm{~A}-\mathrm{C}$ ). This can be accounted to the decreasing ratio of base structure size to the constant CCLD treatment size.
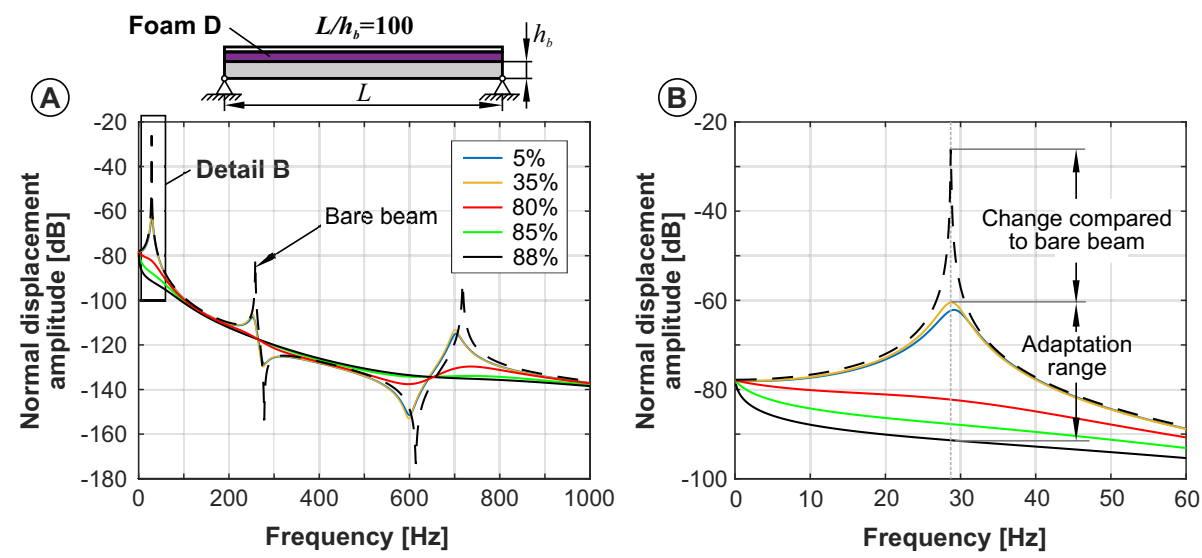

Figure 5. Exemplary normal displacement spectrum at the centre $L / 2$ of the beam (due to this location, the peaks visible in diagram represent the odd bending modes 1,3 and 5) calculated using the extended analytical model: (A) Comparison of the vibration amplitudes of the bare beam (dashed line) and beam with CCLD at different compression levels, (B) Detailed view of the frequency range around the first eigenfrequency and graphical explanation of the key CCLD efficiency indicators for that frequency presented compactly in Figure 6 for all considered foam materials and slenderness values.
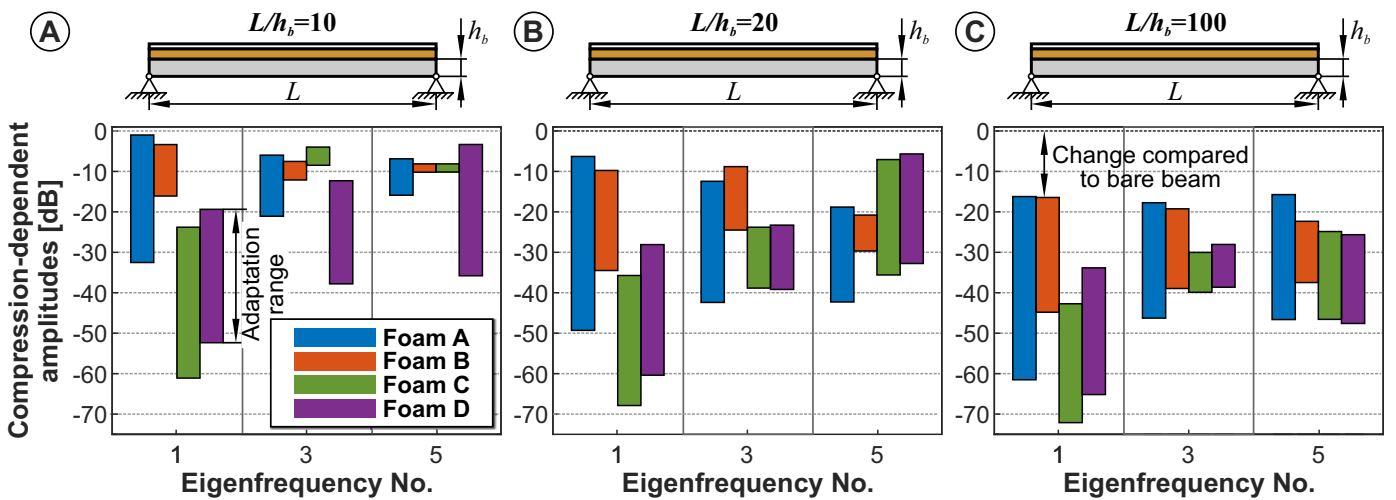

Figure 6. Adaptation ranges of the CCLD-beam's dynamic behaviour in comparison with the bare beam behaviour (reference level at $0 \mathrm{~dB}$ ) for different foam materials and slenderness values: (A) 10, (B) 20, (C) 100. For the definition of of the parameters "Adaptation range" and "Change compared to bare beam" cp. Figure 5 .

The results of the simulations described up to this point confirm the principal correctness of the initial theoretical assumptions about the adaptive dynamic behaviour of structures with the original CCLD treatment. A significant vibration damping as well as a remarkable adaptability (through effects occurring during a simple compressive actuation of the intermediate layer) were observed but both show a complex dependence on the system configuration. Nevertheless, the developed analytical modelling approach can already be used for a preliminary system design. An extensive exploration of the parameter space with the aim of detecting their possible dependencies will be part of future work. The viability of such exploration is supported through the intrinsically moderate computational effort connected with simulations using the analytical model. 


\section{Preliminary Investigations on Textile-Based Ccld}

While the investigations so far focussed on foam-based compressible viscoelastic layers, other material groups are also considered. The already described criteria (Section 2) were applied for a set of alternative materials. It has been found that polyester needle-punched nonwovens (PNPN) in particular shall meet these requirements and also exhibit strong compression-dependent shear properties. Thus, first experiments to determine the shear properties were conducted on cylindrical specimens (diameter: $25 \mathrm{~mm}$, height: $3.4 \mathrm{~mm}$ ) of a commercially available PNPN material using a rotatory rheometer (MCR 502, Co. Anton Paar) in plate plate mode with the same set-up as used for the characterisation of the foam materials [35]. The average diameter of the polyester fibres was determined experimentally at $25 \mu \mathrm{m}$ (Figure 7), the density of the sample at $160 \mathrm{~kg} / \mathrm{m}^{3}$.

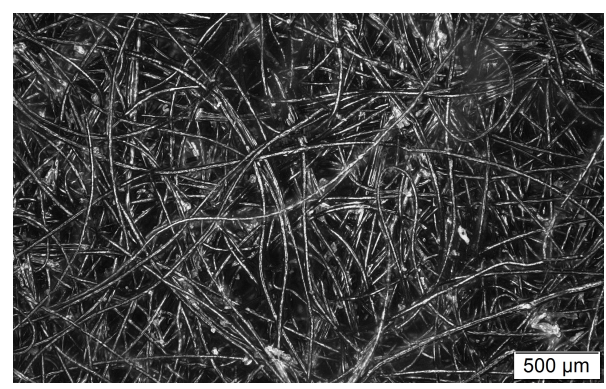

Figure 7. Optical microscope image (bright-field) of the analysed polyester needle punched nonwovens (PNPN) material with clearly visible randomly arranged polyester fibres. Focus stacking has been used for a image with a greater depth of field.

Figure 8 shows a comparison of the shear stress versus shear deformation for the PNPN material (blue curves) and the previously introduced foam $\mathrm{D}$ (red curves). To compare the materials with each other, three pressure levels were selected: $5 \mathrm{kPa}$ (Figure 8A), $13 \mathrm{kPa}$ (Figure 8B) and $49 \mathrm{kPa}$ (Figure 8C). This resulted in a foam compression of $19 \%, 80 \%$ and $89 \%$ and a PNPN compression of $5 \%, 10 \%$ and $20 \%$ respectively. Thus, the same pressures generate significantly less compression of the PNPN.

(A) Compression level 1

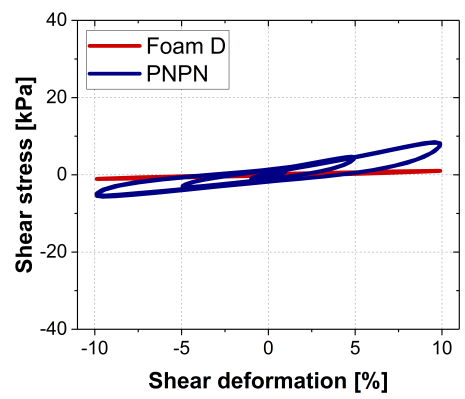

(B) Compression level 2

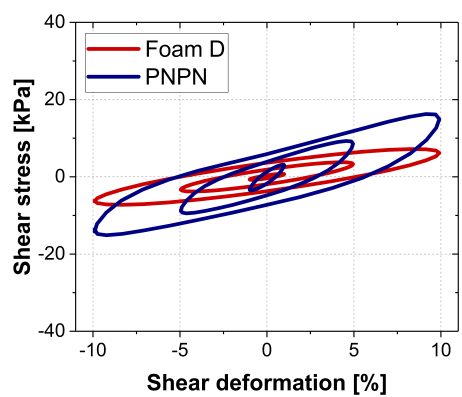

(C) Compression level 3

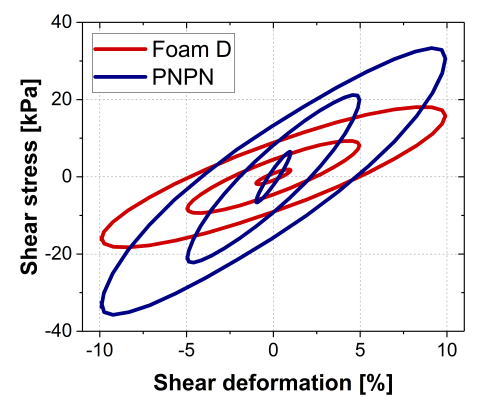

Figure 8. Shear stress versus shear deformation for PNPN in comparison with foam D for three different shear deformation amplitudes at a compression pressure levels of (A) $5 \mathrm{kPa}$, (B) $13 \mathrm{kPa}$ and (C) $49 \mathrm{kPa}$. The area enclosed by the curves represents the dissipated energy per vibration cycle and the slope of major axis the shear stiffness. The curves represent the raw data obtained using the rotatory rheometer configuration mentioned in Section 2. This result presentation was selected instead of listing storage and loss shear moduli due to the noticeable non-linear behaviour of the tested nonwovens.

When examining the results obtained, some interesting aspects become apparent. First, the dissipated energy per vibration cycle-represented by the enclosed area-is for PNPN much higher than for foam D. In order to illustrate this, the damping ratio (dissipated energy of PNPN divided by dissipated energy of foam D) is given in Table 3. Especially with low compression ( $5 \mathrm{kPa})$ and small shear deformation (1\%), the difference is particularly huge (factor 21.5). At high compression 
(49 $\mathrm{kPa}$ ) and large shear deformation (10\%) the dissipated energy of PNPN is still factor 1.6 higher than that of foam $\mathrm{D}$, characterised by the highest storage and loss moduli among the tested foams. Secondly, both materials reveal a strong dependence of shear stiffness from compression, expressed by the increasing slopes of the main axes of the ellipses, which can be an advantageous feature for system detuning in resonance-like conditions. As for the damping ratio, a stiffness ratio is shown in Table 3 . Since the non-linear behaviour of the PNPN entails that the use of the storage module as a measure of stiffness is no longer valid, the slope of the major axes was chosen as a measure of the average stiffness and these values were divided by each other.

Table 3. Comparison of damping and stiffness ratios of PNPN and foam D at different compression pressure levels and shear deformations.

\begin{tabular}{|c|c|c|c|c|c|c|c|c|c|}
\hline \multirow{2}{*}{$\begin{array}{l}\text { Shear Deformation Amplitude } \\
\text { Compression Pressure }\end{array}$} & \multicolumn{3}{|c|}{$1 \%$} & \multicolumn{3}{|c|}{$5 \%$} & \multicolumn{3}{|c|}{$10 \%$} \\
\hline & $5 \mathrm{kPa}$ & $13 \mathrm{kPa}$ & $49 \mathrm{kPa}$ & $5 \mathrm{kPa}$ & $13 \mathrm{kPa}$ & $49 \mathrm{kPa}$ & $5 \mathrm{kPa}$ & $13 \mathrm{kPa}$ & $49 \mathrm{kPa}$ \\
\hline Damping ratio PNPN/Foam D & 21.5 & 3.8 & 2.3 & 13.7 & 2.4 & 1.9 & 10.7 & 2.0 & 1.6 \\
\hline Stiffness ratio PNPN/Foam D & 8.5 & 4.6 & 3.8 & 8.8 & 2.6 & 2.5 & 8.3 & 2.5 & 2.0 \\
\hline
\end{tabular}

While considering the deviation from ideally viscoelastic behaviour taking into account the stress-deformation curves (Figure 8) of the PNPN, following relations can be preliminary identified:

- the decreasing compression level causes that the PNPN has an increasing frictional character. This can be explained by the reduction of the normal forces and through it by the reduction of the stiction forces,

- with increasing shear deformation also the influence of the frictional damping component on the overall damping behaviour increases.

On the one hand, a PNPN-based CCLD treatment requires sophisticated control algorithms regarding their friction-originating non-linear behaviour. On the other hand, such a treatment would exhibit qualitatively new properties in terms of damping capacity and low actuation strokes.

Since no comparable studies can be found in the literature, the presented investigations on exemplary PNPN material may not be fully representative for dry technical textiles used as damping layer in CCLD treatment. However, deeper investigations to confirm the findings as well as studies on the mechanical behaviour at broader excitation parameters are planned.

\section{Outlook}

Further development of CCLD treatment regarding geometrical configuration as well as an attempt to apply a partial coverage of the CCLD is planned. Moreover, application of CCLD for practically-relevant curved structures will be analysed. Such application involves a number of qualitatively new physical effects and requires a considerable extension of the already elaborated design strategies.

The investigations presented in Section 4 show that textile-based CCLD is a promising approach and will be pursued in further studies. Such materials are characterised by high abrasion resistance and can be applied-in contrary to foams-at much higher temperatures. However, in order to be capable to estimate the potential of textile-based CCLD-for example, using the parametric analytical model (Section 3) - the storage and loss shear moduli of PNPN material must be determined in a broad frequency range. Since the established material characterisation techniques and the respective devices cannot cover the frequency range present during real-life operation, time-temperature superposition principle is necessary. Nevertheless, special attention must be paid to the non-linear material behaviour of the PNPN so that the time-temperature analogy remains valid. These advanced studies will be part of future research. 


\section{Conclusions}

For the adaptation of the dynamic behaviour, an original concept of Compressible Constrained Layer Damping (CCLD) was proposed. The control principle bases on minimal deformation of the intermediate, viscoelastic layer when actuated by for example, hydraulic fluid, compressed air or vacuum. Such approach enables an adjustment of the damping and stiffness properties of the overall vibrating system.

Since, the compression-dependent shear damping/stiffness as a parameter of key importance could not be found for polymeric foams extensive material testing was performed. Finally, three PU foams and a melamine foam (as a material with completely different morphology) with favourable viscoelastic properties and significantly different densities were used in the investigations. To estimate the potential of the CCLD, an analytical model was developed which describes the dynamic behaviour of a beam structure, taking into account the compression-driven properties of the intermediate layer. The model was used in a series of simulations to analyse the CCLD potential regarding the damping capacity and its adaptation as well as to understand the physical relationships of parameters describing the system configuration. The influence of the base beam slenderness on the CCLD performance is presented in this study. It can be observed that already the application of an unactuated CCLD on the bare beam increases the system's damping. This can be accounted to a purely passive CLD treatment and it ensures a favourable fail-safe system feature. An understandable trend showing decreasing vibration amplitudes for more slender beams can be observed directly. This can be accounted to the decreasing ratio of base structure size to the constant CCLD treatment size. The results of the simulations confirm the principal correctness of the initial theoretical assumptions about the adaptive dynamic behaviour of structures with the original CCLD treatment. A significant vibration damping as well as a remarkable adaptability were observed but both show-as the results of the material characterisation-a complex dependence on the system configuration.

Alternative damping materials that exhibit higher specific dissipation energies combined with lower actuation strokes compared to polymeric foams were screened. Herein, polyester needle-punched nonwovens (PNPN) were identified as a promising candidate. First preliminary investigations revealed that the damping capacity is between 1.6 (high compression, large shear deformation) and 21.5 (low compression, small shear deformation) times better than that of the polymeric foams focused so far. These results are encouraging but further studies are necessary as non-linear material behaviour was observed under shear stress due to the now different type of dissipation mechanism.

Author Contributions: Conceptualization, T.E. and P.K.; Data curation, T.E.; Formal analysis, K.H. and P.K.; Funding acquisition, N.M. and P.K.; Investigation, T.E.; Project administration, P.K.; Resources, N.M.; Software, K.H.; Supervision, N.M. and P.K.; Validation, P.K.; Visualization, T.E.; Writing-original draft, T.E. and K.H.; Writing-review \& editing, N.M. and P.K.

Funding: Funded by the Deutsche Forschungsgemeinschaft (DFG, German Research Foundation) -315011510. The presented work is part of the research within the context of the Priority Program (SPP 1897) "Calm, Smooth and Smart-Novel Approaches for Influencing Vibrations by Means of Deliberately Introduced Dissipation", subproject "Lightweight Structures with Adaptive Dynamic Behaviour through Evanescent Morphing".

Acknowledgments: Open Access Funding by the Publication Funds of the TU Dresden.

Conflicts of Interest: The authors declare no conflict of interest.

\section{Abbreviations}

The following abbreviations are used in this manuscript:

CT Computed tomography

CCLD Compressible Constrained Layer Damping

CLD Constrained Layer Damping

PNPN Polyester needle-punched nonwovens

PU Polyurethane

TTS Time-temperature superposition 


\section{Appendix A}

(A)

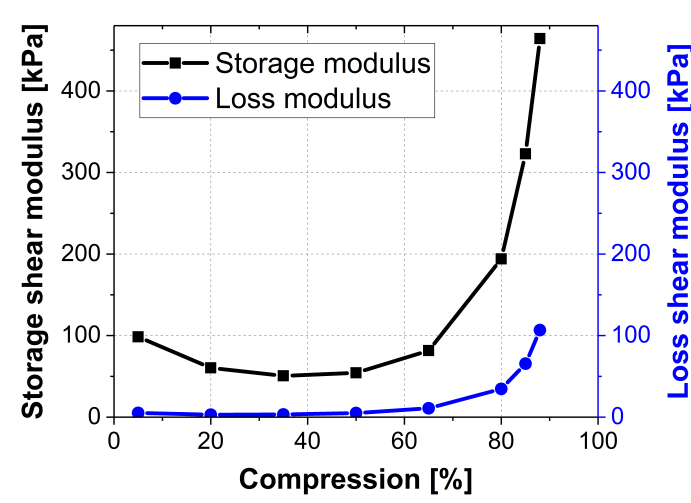

(C)

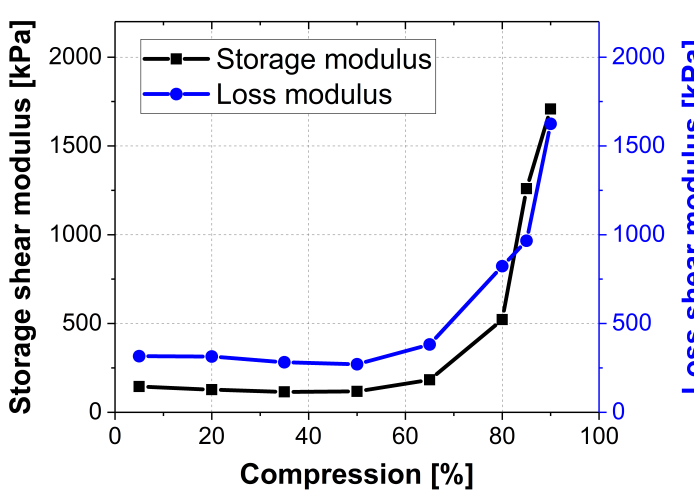

(B) Foam B

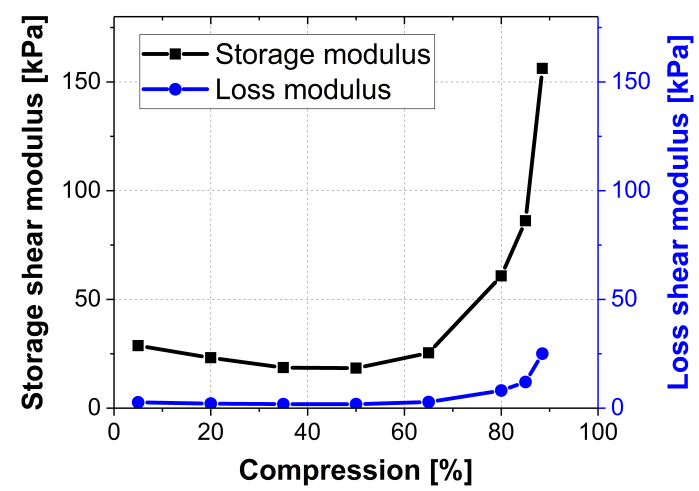

(D) Foam D

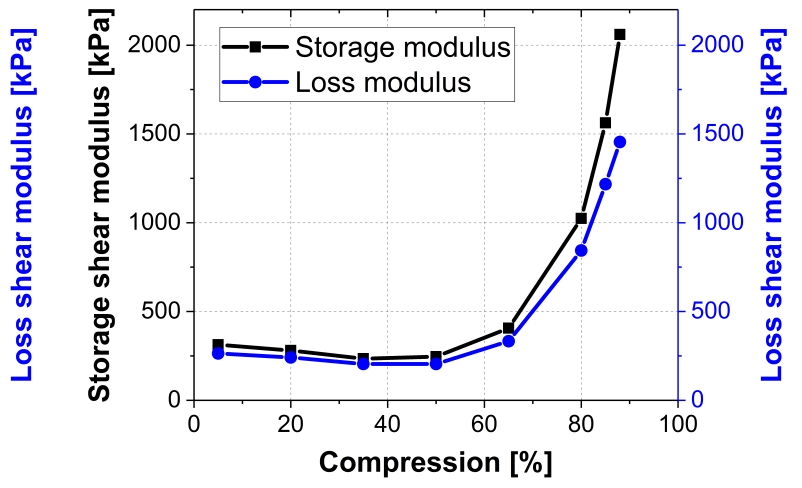

Figure A1. With TTS calculated storage and loss shear moduli versus foam compression of foam A-D (A-D) at $f=100 \mathrm{~Hz}$ and $T=23^{\circ} \mathrm{C}$. For better comparison of storage and loss shear modulus the same scale range was plotted for both values. Due to the fact that the compression dependency introduces an additional dimension to the typical characterisation of the viscoelastic shear behaviour, the presentation of the full set of results is beyond the scope of the current article and can be found in Reference [35].

\section{References}

1. Aggogeri, F.; Borboni, A.; Merlo, A.; Pellegrini, N.; Ricatto, R. Vibration Damping Analysis of Lightweight Structures in Machine Tools. Materials 2017, 10, 297. [CrossRef] [PubMed]

2. Holeczek, K.; Kostka, P.; Modler, N. Dry Friction Contribution to Damage-Caused Increase of Damping in Fiber-Reinforced Polymer-Based Composites. Adv. Eng. Mater. 2014, 16, 1284-1292. [CrossRef]

3. Kostka, P.; Holeczek, K.; Höhne, R.; Filippatos, A.; Modler, N. Extension and application of dynamic mechanical analysis for the estimation of spatial distribution of material properties. Polym. Test. 2016, 52, 184-191. [CrossRef]

4. Kostka, P.; Holeczek, K.; Hufenbach, W. A new methodology for the determination of material damping distribution based on tuning the interference of solid waves. Eng. Struct. 2015, 83, 1-6. [CrossRef]

5. Yang, J.S.; Ma, L.; Schmidt, R.; Qi, G.; Schröder, K.U.; Xiong, J.; Wu, L.Z. Hybrid lightweight composite pyramidal truss sandwich panels with high damping and stiffness efficiency. Compos. Struct. 2016, 148, 85-96. [CrossRef]

6. Koch, S.; Duvigneau, F.; Duczek, S.; Woschke, E. Vibration reduction in automotive applications based on the damping effect of granular material. In Automotive Acoustics Conference 2017; Caprioli, D., Ed.; Springer Fachmedien Wiesbaden GmbH and Springer Vieweg: Wiesbaden, Germany, 2019; Volume 102, pp. 43-57. [CrossRef] 
7. Krause, D.; Paetzold, K.; Wartzack, S. Additively Manufactured Components for Structural Applications in Aircraft Interior-Two Case Studies. In Proceedings of the 27th Symposium Design for X (DFX 2016), Jesteburg, Germany, 5-6 October 2016; pp. 147-156. [CrossRef]

8. Lee, J.Y.; Jeon, W. Vibration damping using a spiral acoustic black hole. J. Acoust. Soc. Am. 2017, $141,1437$. [CrossRef]

9. Dorn, M.; Blech, C.; Langer, S.C. Numerical studies on the optimal exploitation of the acoustic black hole effect in curved panels. Int. Congr. Expo. Noise Control. Eng. Taming Noise Mov. Quiet 2017, 255, 4194-4204.

10. Schmied, J.U.; Sugino, C.; Bergamini, A.; Ermanni, P.; Ruzzene, M.; Erturk, A. Toward structurally integrated locally resonant metamaterials for vibration attenuation. In Proceeding SPIE 10164, Active and Passive Smart Structures and Integrated Systems; International Society for Optics and Photonics: Portland, OR, USA, 2017; Volume 1016413. [CrossRef]

11. Hammami, C.; Balmes, E.; Guskov, M. Numerical design and test on an assembled structure of a bolted joint with viscoelastic damping. Mech. Syst. Signal Process. 2016, 70-71, 714-724. [CrossRef]

12. Greiner-Petter, C.; Tan, A.S.; Sattel, T. A semi-active magnetorheological fluid mechanism with variable stiffness and damping. Smart Mater. Struct. 2014, 23, 115008. [CrossRef]

13. Eshaghi, M.; Sedaghati, R.; Rakheja, S. Dynamic characteristics and control of magnetorheological/ electrorheological sandwich structures: A state-of-the-art review. J. Intell. Mater. Syst. Struct. 2016, 27, 2003-2037. [CrossRef]

14. Cho, M.Y.; Kim, J.S.; Choi, S.B.; Kim, G.W. Non-contact tunable damping of a cantilever beam structure embedded with photo-rheological fluids. Smart Mater. Struct. 2016, 25, 025022. [CrossRef]

15. Dohmen, E.; Modler, N.; Gude, M. Anisotropic characterization of magnetorheological materials. J. Magn. Magn. Mater. 2017, 431, 107-109. [CrossRef]

16. Tan, A.S.; Belkner, J.; Stroschke, A.; Sattel, T. Damping adjustment utilizing digital electrorheological valves with parallely segmented electrodes. Smart Mater. Struct. 2019, 28, 075013. [CrossRef]

17. Han, X.; Neubauer, M.; Wallaschek, J. Improved piezoelectric switch shunt damping technique using negative capacitance. J. Sound Vib. 2013, 332, 7-16. [CrossRef]

18. Nečásek, J.; Václavík, J.; Marton, P. Digital synthetic impedance for application in vibration damping. Rev. Sci. Instrum. 2016, 87, 024704. [CrossRef] [PubMed]

19. Mayer, D.; Bein, T.; Buff, H.; Götz, B.; Schwarzhaupt, O.; Spancken, D. Enhanced lightweight design by composites-Results of the EU project ENLIGHT. J. Reinf. Plast. Compos. 2018, 37, 1217-1224. [CrossRef]

20. Marakakis, K.; Tairidis, G.K.; Koutsianitis, P.; Stavroulakis, G.E. Shunt Piezoelectric Systems for Noise and Vibration Control: A Review. Front. Built Environ. 2019, 5, 64. [CrossRef]

21. Haase, T.; Unruh, O.; Algermissen, S.; Pohl, M. Active control of counter-rotating open rotor interior noise in a Dornier 728 experimental aircraft. J. Sound Vib. 2016, 376, 18-32. [CrossRef]

22. Kostka, P.; Holeczek, K.; Hufenbach, W. Structure-integrated Active Damping System: Integral Strain-based Design Strategy for the Optimal Placement of Functional Elements. Int. J. Compos. Mater. 2013, 3, 53-58.

23. Dannemann, M.; Täger, O.; Modler, N. Combined semi-analytical and numerical vibro-acoustic design approach for anisotropic fibre-reinforced composite structures. J. Sound Vib. 2017, 404, 1-14. [CrossRef]

24. Kliem, M.; Høgsberg, J.; Vanwalleghem, J.; Filippatos, A.; Hoschützky, S.; Fotsing, E.R.; Berggreen, C. Damping Analysis of Cylindrical Composite Structures with Enhanced Viscoelastic Properties. Appl. Compos. Mater. 2019, 26, 85-113. [CrossRef]

25. Zhang, D.; Qi, T.; Zheng, L. A hierarchical optimization strategy for position and thickness optimization of constrained layer damping/plate to minimize sound radiation power. Adv. Mech. Eng. 2018, 10, 168781401880325. [CrossRef]

26. Zhou, X.Q.; Yu, D.Y.; Shao, X.Y.; Zhang, S.Q.; Wang, S. Research and applications of viscoelastic vibration damping materials: A review. Compos. Struct. 2016, 136, 460-480. [CrossRef]

27. Holeczek, K.; Koschichow, R.; Schlieter, T.; Ehrig, T.; Kostka, P. Numerical investigations of polymer-based fibre-reinforced structures with fluidically actuated Compressible Constrained Layer Damping. PAMM 2018, 18. [CrossRef]

28. Ehrig, T.; Holeczek, K.; Kostka, P. Experimental investigations of lightweight structures with fluidically actuated Compressible Constrained Layer Damping. Mater. Today Commun. 2018, 16, 204-211. [CrossRef] 
29. White, S.W.; Kim, S.; Bajaj, A.; Davies, P.; Showers, D.; Liedtke, P. Experimental techniques and identification of nonlinear and viscoelastic properties of flexible polyurethane foam. Nonlinear Dyn. 2000, 22, 281-313. [CrossRef]

30. Gong, L.; Kyriakides, S.; Jang, W.Y. Compressive response of open-cell foams. Part I: Morphology and elastic properties. Int. J. Solids Struct. 2005, 42, 1355-1379. [CrossRef]

31. Ramsteiner, F.; Fell, N.; Forster, S. Testing the deformation behaviour of polymer foams. Polym. Test. 2001, 20, 661-670. [CrossRef]

32. Etchessahar, M.; Sahraoui, S.; Benyahia, L.; Tassin, J.F. Frequency dependence of elastic properties of acoustic foams. J. Acoust. Soc. Am. 2005, 117, 1114-1121. [CrossRef]

33. Padhye, R.; Nayak, R.; (Eds.) Acoustic Textiles; Textile Science and Clothing Technology; Springer: Singapore, 2016. [CrossRef]

34. Knöller, A.; Kilper, S.; Diem, A.M.; Widenmeyer, M.; Runčevski, T.; Dinnebier, R.E.; Bill, J.; Burghard, Z. Ultrahigh Damping Capacities in Lightweight Structural Materials. Nano Lett. 2018, 18, 2519-2524. [CrossRef] [PubMed]

35. Ehrig, T.; Modler, N.; Kostka, P. Compression and frequency dependence of the viscoelastic shear properties of flexible open-cell foams. Polym. Test. 2018, 70, 151-161. [CrossRef]

36. Weaire, D.; Fortes, M.A. Stress and strain in liquid and solid foams. Adv. Phys. 1994, 43, 685-738. [CrossRef]

37. Zheng, H.; Cai, C.; Tan, X.M. Optimization of partial constrained layer damping treatment for vibrational energy minimization of vibrating beams. Comput. Struct. 2004, 82, 2493-2507. [CrossRef]

38. Holeczek, K.; Zhou, B.; Kostka, P. Evanescent morphing for tuning the dynamic behavior of composite lightweight structures: Theoretical assessment. Mech. Adv. Mater. Struct. 2019, 10, 1-10. [CrossRef]

(C) 2019 by the authors. Licensee MDPI, Basel, Switzerland. This article is an open access article distributed under the terms and conditions of the Creative Commons Attribution (CC BY) license (http:/ / creativecommons.org/licenses/by/4.0/). 